${ }^{6}$ Gotschlich, E C, Liu, T Y, and Artenstein, M S, fournal of Experimental Medicine, 1969, 129, 1349.

${ }^{7}$ Artenstein, M S, et al, fournal of Infectious Diseases, 1971, 124, 277.

${ }^{8}$ Greenwood, B M, Whittle, H C, and Dominic-Rajkovic, O, Lancet, $1971,2,519$.

${ }^{9}$ Greenwood, B M, and Whittle, H C, Fournal of Infectious Diseases, 1974, 129, 201.

10 Edwards, E A, and Driscoll, W S, Proceedings of the Society for Experimental Biology and Medicine, 1967, 126, 876.
${ }^{11}$ Scott, D W, and Gershon, R K, Clinical and Experimental Immunology, $1970,6,313$.

12 Levine, L, et al, fournal of Pediatrics, 1960, 57, 836.

${ }_{13}$ Greenwood, B M, et al, Lacnet, 1972, 1, 169.

${ }^{14}$ Doumas, B T, Watson, W A, and Biggs, H G, Clinica Chimica Acta, 1971, 31, 87.

15 Artenstein, M S, and Brandt, B L, fournal of Immunology, 1975, 115, 5.

${ }_{16}$ Amsbaugh, D F, et al, fournal of Experimental Medicine, 1972, 136, 623.

17 Whisnant, J K, et al, Lancet, 1971, 2, 895.

\title{
Twenty-four hour monitoring of heart rate and activity in patients with diabetes mellitus: a comparison with clinic investigations
}

\author{
T BENNETT, PATRICIA A RIGGOTT, D J HOSKING, J R HAMPTON
}

British Medical fournal, 1976, 1, 1250-1251

\section{Summary}

Heart rate and activity were recorded continuously in 11 selected diabetics during a normal day, and the observations were compared with results obtained in the same patients in the diabetic outpatient clinic 10 months earlier. Both sets of findings agreed well in heart rate variability and postural tachycardia. In patients with well-controlled diabetes simple tests of reflex cardiovascular control produce results that may be useful in following the course of diabetic autonomic neuropathy.

\section{Introduction}

Simple measurements of heart rate variability and the changes in heart rate and blood pressure elicited by standing can distinguish different categories of autonomic dysfunction in patients with diabetes mellitus. ${ }^{1}$ Nevertheless, it has hitherto been unknown to what extent these simple measurements, generally performed in the diabetic clinic, reflect the behaviour of the cardiovascular system during normal daily activity. We therefore monitored the heart rate and activity patterns of selected diabetics during a normal day and compared the findings with observations made 10-12 months earlier on the same subjects in the diabetic clinic.

\section{Patients and methods}

Eleven patients were selected from a series previously described ${ }^{1-3}$ to include various combinations of normal and abnormal sympathetic and parasympathetic function. Sympathetic function was considered intact if there was: (a) maintenance of blood pressure on standing (baroreflex activation of peripheral vasoconstrictor mechanisms) associated with a moderate tachycardia (baroreflex activation of cardiac

\footnotetext{
Department of Physiology and Pharmacology, University Hospital and Medical School, Nottingham NG7 2UH

T BENNETT, BSC, PHD, lecturer in physiology

PATRICIA A RIGGOTT, BA, medical technician
}

Department of Medicine, General Hospital, Nottingham NG1 6HA D J HOSKING, MD, MRCP, senior medical registrar

J R HAMPTON, DM, FRCP, consultant physician and reader sympathetics $)^{1} ;(b)$ constriction of forearm blood vessels in response to immersion of the face in water during breath-holding (trigeminal receptors in the facial area activating sympathetic vasoconstrictor nerves) $)^{2} ;(c)$ an overshoot in systemic arterial pressure after the Valsalva manoeuvre (baroreflex activation of peripheral vasoconstrictor mechanisms) $)^{3}$; and $(d)$ tachycardia during performance of a mental task (central activation of cardiac sympathetics) ${ }^{2}$. Parasympathetic function was considered intact if there was: (a) pronounced sinus arrhythmia during deep breathing (peripheral and central activation of the cardiac vagus) ${ }^{14} ;(b)$ bradycardia in response to immersion of the face in water during breath-holding (trigeminal receptors in the facial area activating the cardiac vagus $)^{2} ;(c)$ bradycardia in response to systemic arterial hypertension after the Valsalva manoeuvre (baroreflex activation of the cardiac vagus $)^{3}$; and $(d)$ bradycardia in response to systemic arterial hypertension after intravenous infusion of phenylephrine (baroreflex activation of the cardiac vagus). ${ }^{3}$

The patients fell into three groups: group 1 comprised four patients who showed the responses described above and were therefore judged to have intact sympathetic and parasympathetic mechanisms. In group 2 were four patients who showed no signs of cardiac vagal activity but who had intact or only slightly impaired peripheral sympathetic mechanisms. The three patients in group 3 showed no signs of vagal or peripheral vasoconstrictor activity, although cardiac sympathetic control appeared intact ${ }^{1}$; These patients showed considerable postural hypotension accompanied by a dramatic tachycardia. ${ }^{1}$ The diabetes in all patients was well-controlled at the time of the study.

Measurements in clinic-Heart rate variability during deep breathing ${ }^{4}$ and the changes in heart rate and systolic arterial blood pressure in response to standing for five minutes had been measured as described. ${ }^{1}$

Measurements under unrestricted conditions-The patients were visited at home between 9.00 am and 10.00 am on the day of observation. Chest electrodes were applied, and the electrocardiogram (ECG) recorded from these was fed into one channel of a body-borne tape recorder (Oxford Instruments). A pedometer ${ }^{5}$ capable of distinguishing sustained activity, intermittent activity, and standing was fitted to one foot of the patient and the output was fed into another channel of the tape recorder. Patients were also given diary cards to fill in with information about specific activities. The recording was continued for 24 hours. The tape recorder, pedometer, and diary card were collected the next day. The tapes were played back at 25 times real time, the ECG being passed through a ratemeter to give a value for instantaneous heart rate. ECG, heart rate, and pedometer output were recorded on an ultraviolet monitor. By reference to the pedometer output and diary cards the continuous heart rate recording was examined in terms of the patient's activities.

\section{Results}

The mean heart rate of the subjects in group 3 was higher than that of those in groups 1 and 2, although during sleep or while sitting the 
TABLE I-Mean ( $\pm S E$ of mean) heart rates (beats/min) during sleep, after rising (standing), while sitting, and during intermittent or sustained activity

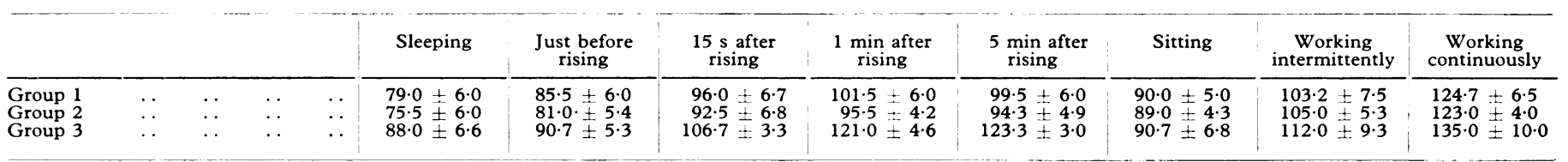

Differences between mean heart rates for groups 1 and 2 compared with group 3 were significant $(\mathbf{P}<0.05)$ only during standing.

TABLE II-Mean heart rate ( \pm 1 SE of mean) for one subject in group 3 during various daily pursuits. Heart rates recorded during driving and working were sustained for one and two hours respectively

\begin{tabular}{|c|c|c|c|c|c|c|}
\hline & Sitting & After insulin & Eating & Defecating & Driving & Working \\
\hline Heart rate $/ \min$ : & $105 \cdot 0 \pm 5 \cdot 0$ & $121 \cdot 0 \pm 5 \cdot 0$ & $131 \cdot 0 \pm 6 \cdot 0$ & $152 \cdot 0 \pm 6 \cdot 0$ & $146 \cdot 0 \pm 6 \cdot 0$ & $148 \cdot 0 \pm 6 \cdot 0$ \\
\hline
\end{tabular}

difference was not significant (table I). The difference in heart rate became more pronounced and reached a level of significance when the subjects rose from bed in the morning.

Under the conditions of unrestricted recording patients undertook different activities, so direct comparison of heart rates during activity might be misleading. Nevertheless, the mean heart rate of patients in group 3 was only 12 beats/min higher during sustained activity than it was during standing (table I), while differences of 25 beats/min and 29 beats/min were found under these conditions for groups 1 and 2 respectively.

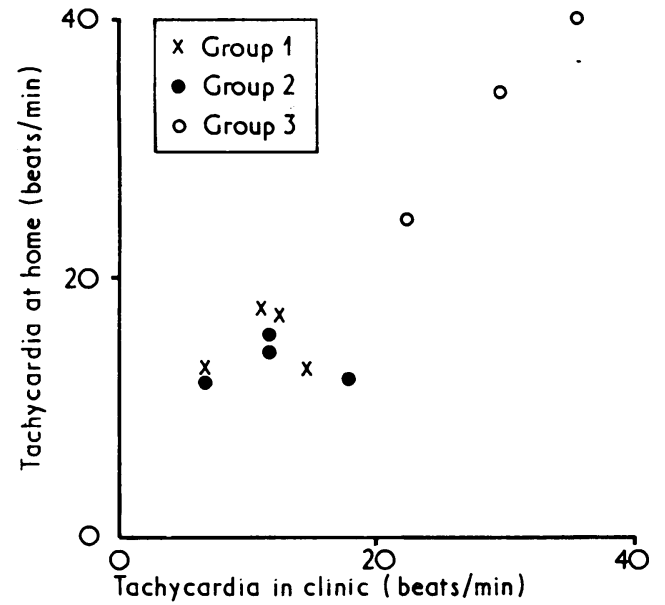

FIG 1-Relation between postural tachycardia observed in clinic and that recorded after rising from bed for 11 diabetics.

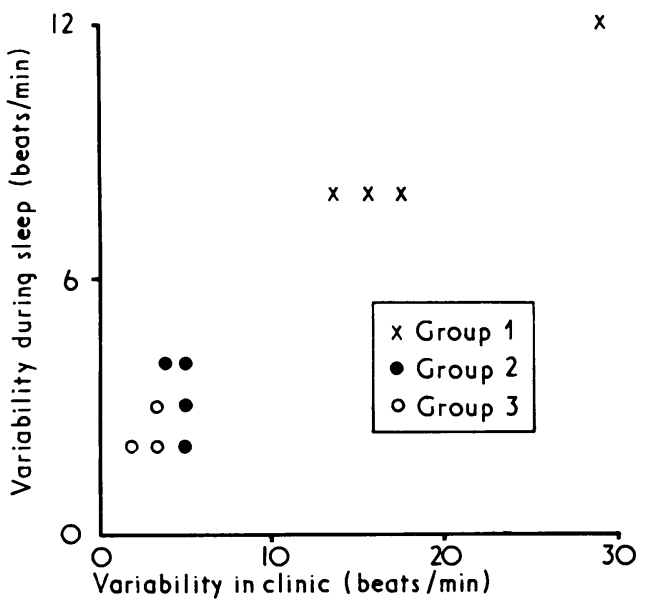

FIG 2-Relation between heart rate variability during deep breathing (in clinic) and during sleep for all subjects.
Patients with normal vagi and normal postural adaptation generally had variable resting heart rates during the day, while those with vagal dysfunction and orthostatic abnormalities had fixed resting heart rates. Two of the subjects in group 3 spent most of the day with a resting (sitting) heart rate fixed at 86 beats $/ \mathrm{min}$ and 82 beats $/ \mathrm{min}$. The other patient in this group is of particular interest since she was very active in spite of markedly abnormal cardiovascular reflexes (table II).

The increase in heart rate seen on rising from bed in the morning was related to that seen in response to standing in the clinic (fig 1). Although heart rate variability was less during sleep than during deep breathing in the clinic the distinction between patients with functional vagi-that is, those with marked sinus arrhythmia-and those with vagal dysfunction - that is, those with little sinus arrhythmia - was evident, even during sleep (fig 2). In group 1 the mean heart rate variability during deep breathing was $19.8 \pm 3.0$ beats $/ \mathrm{min}$ compared with $3.8 \pm 0.4$ beats $/ \mathrm{min}$ for groups 2 and $3(\mathbf{P}<0.001)$. During sleep the values were $9 \cdot 0 \pm 1 \cdot 0$ beats $/ \mathrm{min}$ for group 1 and $2 \cdot 8 \pm 0.3$ beats $/ \mathrm{min}$ for groups 2 and $3(\mathrm{P}<0.001)$.

\section{Discussion}

Our results indicate that simple measurements of cardiovascular function made in the clinic may fairly represent the values that exist during unrestricted daily activity in diabetic patients. Since our 24-hour observations were made 10-12 months after the observations in the clinic, it is of interest that little change had occurred in the cardiovascular status of these patients; this confirms that the progression of neuropathy in well-controlled diabetics may be slow.

Although cardiovascular dysfunction in diabetes may be severe (as in the patients in group 3), it is apparent that this is not necessarily accompanied by troublesome symptoms. Thus one patient with vagal loss and abnormal orthostatic reflexes led a very active life, even though her heart rate was above 130 beats/min for most of the day and was often as high as 150 beats/min without any demanding physical exercise being undertaken. Such a persistent tachycardia may be relevant to the high incidence of and mortality following myocardial infarction. ${ }^{6}$

This work was supported by a grant from the Nuffield Foundation.

Requests for reprints should be sent to Dr T Bennett.

\section{References}

1 Bennett, T, Hosking, D J, and Hampton, J R, British Medical fournal, $1975,2,585$

2 Bennett, T, Hosking, D J, and Hampton, J R, Cardiovascular Research, 1976, 10, 192.

${ }^{3}$ Bennett, T, Hosking, D J, and Hampton, J R, Fournal of Neurology, Neurosurgery, and Psychiatry, 1976, 39, 178.

4 Wheeler, T, and Watkins, P J, British Medical fournal, 1973, 4, 584.

5 Barber, C, et al, Fournal of Physiology, 1973, 231, $291 \mathrm{P}$.

- Soler, N G, et al, Quarterly fournal of Medicine, 1975, 44, 125. 